\title{
Genetic Variability, Correlation and Path Coefficient Analysis of Linseed (L/Numusitatissimum L) Genotypes
}

\author{
Fekadu Amsalu* \\ Holetta Agricultural Research Center P. O. Box 2003, Addis Ababa, Ethiopia
}

*Corresponding Authors: Fekadu Amsalu, Holetta Agricultural Research Center P. O. Box 2003, Addis Ababa, Ethiopia

\begin{abstract}
The experiment was carried out to assess genetic variability, trait association and path coefficient analysis for linseed genotypes in order to select the desired plant types for high yield, oil and their components. The experiment was carried out in Randomized Complete Block Design in three replications at Holetta, Bekoji, Kulumsa and Asasa Agricultural Research Centres. The results of combined analysis indicated that studied traits of genotypes for yield and its related component traits were highly and significantly different for all traits compared. This revealed that there was a considerable magnitude of variability among the different genotypes for all the traits. In genetic variability, heritability and genetic advance analysis yield per plot (330946.300, 112402.07), oil yield (59119.073, 22288.127), plant height (156.390, 58.435649), days to flowering 29.102, 1170926), date of 50\% maturity (28.826, 5.739815), and oil content(8.045,3.9981945) showed high phenotypic and genotypic variances, respectively indicating that the genotypes could be reflected by the phenotype and the effectiveness of selection based on the phenotypic performance for these traits. Oil content (49.700\%), days to flowering (40.235\%), oil yield (37.700\%) plant height (33.365\%) and seed yield (33.964\%), exhibited high heritability estimates. In the other hand only days to maturity $(19.912 \%)$ showed medium heritability trait. In genotypic correlation seed yield per plot showed highly significant and positive correlation with oil yield ( $r$ : $0.99353)$ and date of $50 \%$ maturity ( $r$ : 0.79637), significant positive with oil content ( $r$ : 0.70134) which indicates that taking into account oil yield, and $50 \%$ maturity date as selection parameter will be an effective way to increase seed, and oil yield. Analyzed value from genotypic coefficient of variation, heritability and genetic advance, correlation co-efficient and path coefficient, oil yield, flowering, oil content and plant height were the traits which could be considered for future linseed breeding program.
\end{abstract}

Keywords: linseed, genetic variability, heritability, correlation, path analysis

\section{INTRODUCTION}

In Ethiopia Linseed (Linum usitatissimum L.) is one of the most important oldest plant species cultivated for seed yield and oil traits. It is the second most important oil crops in the highlands of Ethiopia next to noug in terms of area and production with a productivity of about $1.116 \mathrm{t} / \mathrm{ha}$ (CSA, 2017/18). Linseed (Linum usitatissimum L.) $2 x=2 n=30$ is an annual self-pollinated crop.

Linseed is an important oilseed crop and its seed contains good percentage of oil varying from $32 \%$ to $45 \%$ (Adugna and Labuschange, 2002). It's medicinal and nutritional properties have paved the way for its diversified uses and value addition in various forms. Its seed comprises complete protein (rich in eight essential amino acids) higher order linolenic acid (an essential poly unsaturated Omega- 3 fatty acid) highest in plant kingdom. Recent advances in neuron-biology have established that it is best herbal source of Omega-3 and Omega-6 fatty acids which helps in regulating the nervous system. In Ethiopia Linseed is grown mainly for seed use and extracting oil by crushing the seeds. The area under cultivation is approximately 79044.5.1 ha in Ethiopia. Average yield of linseed in Ethiopia is 1.116t/ha which is comparably very low in comparison with world average yield that is $2.75 \mathrm{t} / \mathrm{ha}$ (www.premium crop.com).

In Ethiopia research on linseed started after the establishment of National Oil crops Task force in 1981 by Ethiopian Institute of Agricultural Research with objective of developing high-yielding linseed genotypes with better, stable seed yield and oil contents. In doing so the breeding approaches for linseed improvement remained confined to selection and recombination followed by selection. To address this 
challenge for a better breeding program, it should have a broad genetic base. The success of any breeding program depends upon the genetic variability existed in the breeding material. The existing genetic base of linseed is not enough to meet the challenge. Seed yield is a complex character that can be determined by several components reflecting positive or negative effect upon this trait, whereas it is important to examine the contribution of each of the various components in order to give more attention to those having the greatest influence on seed yield (Marinkovic - Jeromela et al., 2007). Clear awareness of the association between yield and its component traits is a vital importance of making the best use of these relationships in selection. Determination of correlation coefficients is an important statistical procedure to evaluate breeding programs for high yield, as well as to examine direct and indirect contributions to yield variables (Ali et al., 2003). Path coefficient technique splits the correlation coefficients into direct and indirect effect i.e., alternative characters or pathways and thus permits a critical examination of components that influence a given correlation and can be helpful in formulating an efficient selection strategy. Therefore, correlation in combination with the path coefficient analysis quantifies the direct and indirect contribution of one character upon another (Dewey and $\mathrm{Lu}, 1959)$. Hence the present study was conducted to assess the genetic variability, trait association and path coefficient analysis for linseed genotypes in order to select desired plant types for high yield, oil and their component traits in central highlands of Ethiopia.

\section{Materials AND Methods}

The experiment was conducted in experimental field at Holetta, Bekoji, Kulumsa and Asasa Agricultural Research Centre s during 2008/09 cropping season. The test locations are the main testing sites for highland linseed varieties. Those are believed to represent the major crop growing agro ecologies of Ethiopia in the central highland areas. The experiment was carried out to assess genetic variability, correlation and path analysis of Linseed genotypes for seed yield, oil content and their component traits of ten genotypes of linseed against one standard check (Tolle variety). A seed rate of $25 \mathrm{~kg} / \mathrm{ha}$ was utilized to conduct the experiment. Two-hand weeding and fertilizer rate of $23 / 23 \mathrm{~N} / \mathrm{P}_{2} \mathrm{O}_{5} \mathrm{Kg} \mathrm{ha}^{-1}$ was the inputs of improved packages used for assessment purpose on each individual experimental plot. Randomized Complete Block Design with three replications was employed. The gross plot size was six-meter square (six rows of 5meter long and $20 \mathrm{~cm}$ spacing) and the net harvest plot size was four-meter square (four central rows). The four central rows in each plot were used for data recording. By considering the central four rows the pre harvested agronomic data such as 50\% date of flowering, and 50\% date of maturity was recorded. In addition to this plant height of this trait per five plants was collected. Besides pre harvested data, post harvest agronomic data such, seed yield which was obtained from the central four rows, oil content that was measured by using Nuclear Magnetic Resonance spectroscope and oil yield that was also obtained by multiplying seed yield with corresponding oil percentage were taken and statistically analysed using SAS soft ware. Major criteria during the assessment considered were yield and oil production enhancing component traits. In this experiment ten genotypes of Linseed were taken from linseed preliminary trial that were evaluated for the previous season and stocked at Holetta Agricultural Research Centre to represent the available germplasm /breeding stock.

\section{RESULTS AND DISCUSSION}

The results of combined analysis of mean squares of variance are presented in Table 1 . The result indicated that studied traits of genotypes for seed yield and its related component traits were highly and significantly different for seed yield per plot, oil content percent and oil yield $\mathrm{kg} / \mathrm{ha}$, date of flowering and plant height. This revealed that there was a considerable magnitude of variability among the different genotypes for all the traits compared. Similar findings were reported by Akbar et al. (2003). The high amount of genetic variability in the studied genotypes for the major yield contributing traits along with oil content and oil yield indicated that the possibility of further improvement of these traits. Yadava, 1996 reported similar findings pertaining to the presence of high genetic variability for different traits including seed yield per plant

Table1. The mean squares for different sources of variation and the corresponding Coefficient of variation in percent for the six traits studied

\begin{tabular}{|l|l|l|l|l|}
\hline Traits & Replication(2) & Genotype (9) & Error (72) & CV \\
\hline Seed yield & 0.125 & $277875^{* *}$ & 53071.08 & 15.64 \\
\hline Oil content & 0.027 & $8.02052^{* *}$ & 0.02413 & 0.42 \\
\hline
\end{tabular}


Genetic Variability, Correlation and Path Coefficient Analysis of Linseed (L/Numusitatissimum L) Genotypes

\begin{tabular}{|l|l|l|l|l|}
\hline Oil yield & 50803 & $51847.7^{* *}$ & 7271.41 & 15.35 \\
\hline Date of flowering & 6.425 & $26.2602^{* *}$ & 2.84167 & 1.88 \\
\hline Date of maturity & 8.1083 & $20.1528^{*}$ & 8.67315 & 1.95 \\
\hline Plant height & 14.1667 & $136.6306^{* *}$ & 19.759259 & 4.77 \\
\hline
\end{tabular}

** Indicate significance at 0.01 probability level; figures in parenthesis refer to degrees of freedom, CV: Coefficient of variation

\subsection{Mean Performance of Ten Linseed Genotypes for Six Traits}

As indicated in table 2 significant variations were observed among the genotype for days to flowering and days to maturity. Days to flowering ranged from 87 to 91 , days to maturity from 148 to 159 and plant height from 84 to $100 \mathrm{~cm}$. The high yielding genotypes, PGRC/E $10306 \mathrm{X}$ Chilalo $\mathrm{Y} / 3$ (1797kg/ha), Omega X CI-1525/B/44 (1585kg/ha), Omega X CI1525/Y/44 (1559kg/ha), CI-1652 X Omega/B/53 (1529kg/ha) were 87, 87, 89, 91 days in flowering and maturity dates $159,151,151$ and 149 respectively. The late maturity date was for the highest yielding genotype 159 days. As shown in table 2 the tested genotypes, PGRC/E 10306 X ChilaloY/3, OmegaXCI-1525/B/44, Omega X CI1525/Y/44, CI-1652 X Omega/B/53 are first, second, third and fourth in seed yield .But PGRC/E10306 X Chilalo Y/3, CI-1652 X Omega/B/53, PGRC/E10306 X CI-1525/3/B, are first, second and third in oil content percent. Above all the genotypes PGRC/E 10306 X Chilalo Y/3 showed the highest mean value in seed yield, oil content and oil yield from the tested genotypes. In other side from tested genotypes in oil yield the genotypes PGRC/E 10306 X Chilalo Y/3, Omega X CI-1525/B/44, Omega X CI-1525/Y/44, CI-1652 X Omega/B/53 are first, second, third and fourth respectively. In addition all tested genotypes except PGRC/E 10306 X CI-1525/1/A gave the highest seed yield over the mean of the standard check Tolle(1303kg/ha).The yield ranges $1303 \mathrm{~kg} / \mathrm{ha}$ (Tolle) to $1797 \mathrm{~kg} / \mathrm{ha}$ (PGRC/E 10306 $\mathrm{X}$ Chilalo Y/3). Oil content ranges from $35.70 \%$ (Tolle) to $38.39 \%$ (PGRC/E $10306 \mathrm{X}$ Chilalo Y/3). Regarding to oil content and oil yield aspects all tested genotypes gave the highest mean value than standard check. The oil yield ranges from $471 \mathrm{~kg} / \mathrm{ha}$ (Tolle) to $692 \mathrm{~kg} / \mathrm{ha}$ (PGRC/E $10306 \mathrm{X}$ Chilalo $\mathrm{Y} / 3)$.

Table2. Mean performance of ten genotypes of linseed for six different traits studied at Holetta, Bekoji, Kulumsa and Asasa agricultural research centres during 2008/09 cropping season

\begin{tabular}{|c|c|c|c|c|c|c|c|}
\hline \multirow[t]{2}{*}{ No } & \multirow[b]{2}{*}{ Genotype } & \multirow{2}{*}{$\begin{array}{l}\text { Seed } \\
\text { yield } \\
\mathrm{kg} / \mathrm{ha}\end{array}$} & \multirow{2}{*}{$\begin{array}{l}\text { Oil } \\
\text { content } \\
\%\end{array}$} & \multirow{2}{*}{$\begin{array}{l}\text { Oil } \\
\text { yield } \\
\mathrm{kg} / \mathrm{ha}\end{array}$} & \multicolumn{2}{|l|}{ Days to } & \multirow{2}{*}{$\begin{array}{l}\text { Plant } \\
\text { height } \\
\mathrm{Cm}\end{array}$} \\
\hline & & & & & $\begin{array}{l}\text { Flowering } \\
50 \%\end{array}$ & $\begin{array}{l}\text { Maturity } \\
50 \%\end{array}$ & \\
\hline 1 & PGRC/E 10306 X Chilalo Y/3 & 1797 & 38.39 & 692 & 87 & 159 & 93 \\
\hline 2 & PGRC/E 10306 X CI 1525/3/B & 1371 & 37.84 & 521 & 91 & 151 & 95 \\
\hline 3 & Omega X CI 1525/Y/44 & 1559 & 37.39 & 595 & 89 & 151 & 92 \\
\hline 4 & PGRC/E 10306X CI-1525/1/A & 1289 & 36.73 & 479 & 90 & 150 & 91 \\
\hline 5 & CI -1652 X Omega /B/53 & 1529 & 38.21 & 590 & 91 & 149 & 97 \\
\hline 6 & Omega X CI -1525/14/A & 1457 & 37.29 & 545 & 89 & 150 & 96 \\
\hline 7 & Omega X CI -1525/Y/43 & 1394 & 37.58 & 527 & 90 & 150 & 97 \\
\hline 8 & CI-1652 X Omega/B//58 & 1445 & 36.69 & 534 & 90 & 149 & 94 \\
\hline 9 & Omega X CI 1525/B/44 & 1585 & 37.65 & 599 & 87 & 151 & 100 \\
\hline \multirow[t]{4}{*}{10} & Tolle & 1303 & 35.70 & 471 & 91 & 148 & 84 \\
\hline & Mean & 1472 & 37.4 & 556 & 90 & 150 & 93 \\
\hline & $\mathrm{CV}(\%)$ & 15.65 & 0.42 & 15.35 & 1.88 & 1.95 & 4.44 \\
\hline & LSD $(5 \%)$ & 187.48 & 0.08 & 69.39 & 1.37 & 1.51 & 2.88 \\
\hline
\end{tabular}

\subsection{Genetic Variability, Heritability and Genetic Advance}

Estimates of genotypic and phenotypic variances, genotypic coefficient of variation (GCV), phenotypic coefficients of variation (PCV), heritability in broad sense, expected genetic advances and genetic advances as percent mean are given in Table3. Estimated genetic variance ranged from $3.9981945 \%$ for oil content percent to $112402.07 \% \mathrm{~kg} / \mathrm{ha}$ for seed yield per plot. Likewise phenotypic variance ranged from $8.045 \%$ for oil content percent to $330946.300 \%$ for seed yield $\mathrm{kg} / \mathrm{ha}$. Phenotypic coefficients of variation ranged from $3.579 \%$ Date of maturity to $43.731 \%$ for oil yield $\mathrm{kg} / \mathrm{ha}$. Genotypic coefficients of variation ranged from $1.597 \%$ for date of $50 \%$ maturity to $26.851 \%$ for oil yield per plot. Seed yield per plot $(330946.300,112402.07)$, oil yield $(59119.073,22288.127)$, plant height $(156.390,58.435649)$, days to flowering $(29.102,11.70926)$ and days to maturity $(28.826$, 
5.739815) showed high phenotypic and genotypic variances, respectively indicating that the genotypes could be reflected by the phenotype and the effectiveness of selection based on the phenotypic performance for these traits. Likewise, Low genotypic variance was recorded for traits such as oil content percent (3.9981945\%) and date of maturity (5.739815\%). However, high genotypic coefficients of variation (GCV) and phenotypic coefficients of variation (PCV) were shown in traits such as oil yield per plot $(26.851,43.731)$ seed yield per plot $(22.776,39.081)$ respectively, which means selection of these traits based on phenotype characteristics may be useful for oil yield and seed yield per plots improvement program. This result agrees with the findings of Pali and Mehta (2013).

\subsection{Heritability in the Broad Sense}

Breeders can make rapid progress where heritability is high by using selection methods that are dependant solely on phenotypic characteristics (e.g. mass selection). However, where heritability is low methods of selection based on families and progeny testing are more effective and efficient. Heritability estimated using the total genetic variance is called broad sense heritability .Heritability in the broad sense of the traits is presented in Table 3 In this study, heritability values were found to be sufficiently high for most important yield component characters. Dabholkar (1992) generally classified heritability estimates as low (5-10\%), medium (10-30\%) and high (30-60\%). Based on this classification, oil content $(49.700 \%)$, days to flowering $(40.235 \%)$, oil yield $(37.700 \%)$, plant height $(37.365 \%)$ and seed yield $(33.964 \%)$ exhibited high heritability estimates. From tested traits only days to $50 \%$ maturity $(19.912 \%)$ exhibited medium heritability estimates, Oil content was found to be the most heritable trait in the studied genotypes, with heritability of $49.700 \%$, followed by days to flowering $(40.235 \%)$, oil yield $(37.700 \%)$ and seed yield per plot (33.964\%), This indicates that selection for these traits in the genotype would be most effective for the expression of these traits in the succeeding generations. Therefore, good improvement can be made if some of these traits are considered as selection criteria in future breeding program. Similar findings had been reported by Wakijira (2011) for seed yield per plot, date of flowering and plant height. According to Akbar et al.(2003), if the heritability of a character is high, selection for such character is fairly easy as selected character will be transmitted to its progeny. This is because there would be a close correspondence between the genotype and phenotype due to a relatively similar contribution of the environment to the genotype.

Genetic advance

Concerning the genetic advance at 5\% intensity the highest genetic gain was predicted for oil yield per plot $(33.963 \mathrm{~kg})$ followed seed yield plot $(27.344 \mathrm{~kg})$, plant height $(10.350 \mathrm{~cm})$, oil content percent (7.764\%) and while the lowest genetic advance was predicted for date of $50 \%$ maturity date(1.468\%).Genetic advance as a percent mean ranged from $0.979 \%$ date of $50 \%$ maturity to $20.760 \%$ for oil content percent (Table 3). Within this range, a relatively high genetic advance as a percent mean was observed for oil content $20.760 \%$ ) and plant height (11.129\%) followed by oil yield per plot $(6.108 \%)$. On the other hand, the lowest genetic gain as percent of means was observed for date of 50\% maturity (0.979) \%) followed by seed yield per plot (1.858.\%). Low genetic advance as percent means observations in this study indicates that characters probably were under environmental influence than the genotypic expression and that selection based on these traits would be ineffective.

Table3. Estimates of mean performance, range, genetic variance $(G V)$,phenotypic variance $(P V)$, genotypic coefficient of variation $(G C V)$, phenotypic coefficient of variation $(P C V)$, heritability and genetic advance (GA) in different genotypes of linseed

\begin{tabular}{|c|c|c|c|c|c|c|c|c|c|}
\hline $\begin{array}{l}\text { Studied } \\
\text { traits }\end{array}$ & $\begin{array}{l}\text { Mean } \\
\pm \text { S.E }(\mathrm{m})\end{array}$ & $\begin{array}{l}\text { Rang } \\
\text { e }\end{array}$ & GV & PV & GCV & PCV & $\mathrm{H}(\mathrm{bs})$ & GA & $\begin{array}{l}\text { GA } \\
\text { as } \%\end{array}$ \\
\hline $\begin{array}{l}\text { Seed } \\
\text { yield }\end{array}$ & $1472 \pm 1.0245$ & $\begin{array}{l}1289- \\
1797\end{array}$ & $\begin{array}{l}112402.0 \\
7\end{array}$ & $\begin{array}{l}330946.30 \\
0\end{array}$ & $\begin{array}{l}22.77 \\
6\end{array}$ & $\begin{array}{l}39.08 \\
1\end{array}$ & $\begin{array}{l}33.96 \\
4\end{array}$ & $\begin{array}{l}27.34 \\
4\end{array}$ & 1.858 \\
\hline $\begin{array}{l}\text { Oil } \\
\text { content }\end{array}$ & $\begin{array}{l}37.4 \pm 1.0226 \\
0\end{array}$ & $\begin{array}{l}35.70 \\
- \\
38.39\end{array}$ & $\begin{array}{l}3.998194 \\
5\end{array}$ & 8.045 & 5.346 & 7.584 & $\begin{array}{l}49.70 \\
0\end{array}$ & 7.764 & $\begin{array}{l}20.76 \\
0\end{array}$ \\
\hline Oil yield & $556 \pm 1.02278$ & $\begin{array}{l}471- \\
692\end{array}$ & $\begin{array}{l}22288.12 \\
7\end{array}$ & 59119.073 & $\begin{array}{l}26.85 \\
1\end{array}$ & $\begin{array}{l}43.73 \\
1\end{array}$ & $\begin{array}{l}37.70 \\
0\end{array}$ & $\begin{array}{l}33.96 \\
3\end{array}$ & 6.108 \\
\hline $\begin{array}{l}\text { Date of } \\
\text { flowerin } \\
\mathrm{g}\end{array}$ & $90 \pm 1.02465$ & $87-91$ & 11.70926 & 29.102 & 3.802 & 5.994 & $\begin{array}{l}40.23 \\
5\end{array}$ & 4.968 & 5.520 \\
\hline
\end{tabular}


Genetic Variability, Correlation and Path Coefficient Analysis of Linseed (L/Numusitatissimum L) Genotypes

\begin{tabular}{|c|c|c|c|c|c|c|c|c|c|}
\hline $\begin{array}{l}\text { Date of } \\
\text { maturity }\end{array}$ & $150 \pm 1.02537$ & $\begin{array}{l}145- \\
159 \\
\end{array}$ & 5.739815 & 28.826 & 1.597 & 3.579 & $\begin{array}{l}19.91 \\
2\end{array}$ & 1.468 & 0.979 \\
\hline $\begin{array}{l}\text { Plant } \\
\text { height }\end{array}$ & $93 \pm 1.0229$ & $87-97$ & $\begin{array}{l}58.43564 \\
9\end{array}$ & 156.390 & 8.220 & $\begin{array}{l}13.44 \\
7\end{array}$ & $\begin{array}{l}37.36 \\
5\end{array}$ & $\begin{array}{l}10.35 \\
0\end{array}$ & $\begin{array}{l}11.12 \\
9\end{array}$ \\
\hline
\end{tabular}

\subsection{Correlation Coefficient for Linseed Tested Genotypes of Traits}

Genotypic correlation coefficients among yield and its component traits are presented in (table 4). Seed yield per plot showed highly significant and positive correlation with oil yield (r: 0.99353), date of 50\% maturity (r: 0.79637), significant positive with oil content (r: 0.70134) which indicates that taking into account oil yield, date of $50 \%$ maturity and oil content as selection parameter will be an effective way to increase seed, oil percent and oil yield. This result is in agreement with the findings of Abebe (2006), Aytac and Kinaci (2009) who reported positive correlation of seed yield per plot with oil yield per plot and seed yield per plant. Oil content percent showed positively significant correlated association with seed yield per plot(r: 0.70134) and plant height(r: 0.71909) also showed highly and positively association with oil yield (r: 0.77109). Oil yield showed highly and positively correlation with seed yield(r: 0.99353), oil content(r: 0.77109) and date of maturity(r: 0.79612). Date of flowering showed negative significant correlation for all studied traits except for oil content and plant height which are not significant. Similarly date of maturity showed positive significant association with seed yield (r: $0.79637)$ and highly significance of oil yield(r $: 0.79612)$ traits. Hence making simultaneous increase for these characters with yield per plot, oil content and oil yield is difficult. From these results, we may extract that indirect selection for earliness for days to maturity; shortness of plant height will be worthwhile in improvement of the seed, oil and oil yield. Association of plant height with oil content showed positive significance correlation (r: 0.71909). On the other hand for seed yield, oil yield and date of $50 \%$ maturity studied traits it showed positive non significant correlation.

Table4. Genotypic correlation coefficients for combination of six traits in studied linseed genotypes

\begin{tabular}{|c|l|l|l|l|l|l|}
\hline & Sy & Oc & Oy & Df & Dm & Ph \\
\hline Sy & 1.000 & $0.70134^{*}$ & $0.99353^{* *}$ & $-0.77126^{* *}$ & $0.79637 * *$ & $0.37057 \mathrm{~ns}$ \\
\hline oc & $0.70134^{*}$ & 1.000 & $0.77109^{* *}$ & $-0.39738 \mathrm{~ns}$ & $0.60716 \mathrm{~ns}$ & $0.71909^{*}$ \\
\hline oy & $0.99353^{* *}$ & $0.77109^{* *}$ & 1.000 & $-0.73347^{*}$ & $0.79612^{* *}$ & $0.41764 \mathrm{~ns}$ \\
\hline df & $-0.77126 * *$ & $-0.39738 \mathrm{~ns}$ & $-0.7334^{*}$ & 1.000 & $-0.70052 * *$ & $-0.36113 \mathrm{~ns}$ \\
\hline dm & $0.79637 *$ & $0.60716 \mathrm{~ns}$ & $0.79612^{* *}$ & $-0.70052^{*}$ & 1.000 & $0.11478 \mathrm{~ns}$ \\
\hline ph & $0.37057 \mathrm{~ns}$ & $0.71909^{*}$ & $0.41764 \mathrm{~ns}$ & $-0.36113 \mathrm{~ns}$ & $0.11478 \mathrm{~ns}$ & 1.000 \\
\hline
\end{tabular}

Sy: seed yield, Oc : Oil content, Oy: oil yield, $d f$, date of flowering, Dm: Date of maturity, , Ph: plant height,

\subsection{Genotypic Path Coefficient Analysis}

Association of traits determined by correlation coefficient may not provide the exact picture of the relative importance of direct and indirect influence of each yield component traits on yield. Correlation coefficients were partitioned into direct and indirect effect to find out a clear picture of the interrelationship between yield and other yield related traits by using path analysis. The results of path coefficient analysis for studied traits were indicated in table 5. Path coefficient analysis showed that the oil yield had highest positive direct effect on seed yield per plot (2.23). It had positive indirect effect on seed yield, i.e. oil content (2.52) followed by date of maturity (1.58), plant height (1.19), date of flowering (0.98). Finally it made highly significant positive correlation with seed yield per plot ( $\mathrm{rg}=$ $0.99353^{* *}$ ), date of maturity (rg: $0.79612^{* *}$ ) and oil content (rg: 0.70134**). In other hand it had showed significantly negative correlation with 50\% date of flowering (rg:-0.77126*) and positive non significant correlation with plant height(r: 0.37057). The genotypic correlation of seed yield per plot, oil content and date of maturity was positive and considerably higher in magnitude. It is mainly due to high positive direct effect and positive indirect effects of other traits. Therefore, selection would be effective for seed yield per plot, oil content and oil yield. Date of flowering had positive direct effect on seed yield per plot (1.81) and positive indirect effect on seed yield by oil yield(2.89) followed by date of maturity(2.07) oil content (1.95) and plant height (0.69). Date of maturity had negative direct effect on seed yield per plot $(-1.82)$ and negative indirect effect on date of $50 \%$ flowering $(-2.47)$ followed by oil yield (-2.12), oil content (-1.00) and plant height $(-0.60)$. Plant height had positive direct effect on seed yield per plot (0.19) and positive indirect effect on date of maturity (2.60), oil yield(2.30), date of flowering(1.73)and oil content(1.53). The path coefficient analysis indicated that oil yield, date 
of flowering, oil content and plant heights were the most important contributors to seed yield per plot which could be taken in to consideration for future breeding program. Wide variability has been found among the genotypes for all the studied traits. The result of the study will provide the ability of breeders to develop desirable plant types having high seed yield, oil content and oil yield with early maturity. Analyzed value from genotypic coefficient of variation, heritability and genetic advance in percent of mean, correlation co-efficient and even path coefficient indicates oil content, oil yield, date of flowering and plant height were such traits which could be considered for future linseed crop breeding program.

Table5. Genotypic path coefficient analysis showing direct (bold) and indirect effects of different traits in linseed genotype

\begin{tabular}{|l|l|l|l|l|l|l|}
\hline & OC & OY & DF & DM & PH & SY \\
\hline OC & $\mathbf{1 . 7 7}$ & 2.87 & 1.91 & 2.07 & 0.62 & $0.70134^{*}$ \\
\hline OY & 2.52 & $\mathbf{2 . 2 3}$ & 0.98 & 1.58 & 1.19 & $0.99353^{* *}$ \\
\hline DF & 1.95 & 2.89 & $\mathbf{1 . 8 1}$ & 2.07 & 0.69 & $-0.77126^{* *}$ \\
\hline DM & -1.00 & -2.12 & -2.47 & $\mathbf{- 1 . 8 2}$ & -0.60 & $0.79637^{* *}$ \\
\hline PH & 1.53 & 2.3 & 1.73 & 2.60 & $\mathbf{0 . 1 9}$ & $0.37057 \mathrm{~ns}$ \\
\hline
\end{tabular}

Sy: seed yield, Oc: Oil content, OY: oil yield, DF, Date of flowering, DM: Date of maturity, PH: plant height

\section{CONCLUSION}

The present study was carried out to assess the genetic variability, trait association and path coefficient analysis for Linseed genotypes which are very important for an effective breeding program to select desired plant types to meet the arising demand for high seed yield, oil content and oil yield traits in central highlands of Ethiopia. Studied traits of genotypes for seed yield and its related component traits were highly and significantly different for seed yield, oil content and oil yield, date of $50 \%$ flowering and plant height. This revealed that the presence of a considerable magnitude of variability among the different genotypes of Linseed for all the traits studied.

The high amount of genetic variability in the studied genotypes for the major yield contributing traits along with oil content and oil yield indicated that the existing possibility for the further improvement of these traits. Phenotypic correlation coefficients were higher in magnitude than their respective genotypic correlation coefficients for most of the traits indicating the environmental influence on phenotypic expression. In genotypic correlation coefficients analysis Seed yield per plot showed significant and positive correlation with oil yield, oil content and 50\% date of maturity which indicates that taking into account oil yield, oil content and $50 \%$ maturity date, as selection parameter will be an effective way to increase seed oil content and oil yield. The path coefficient analysis indicated that oil yield, date of 50 flowering, oil content and plant heights were the most important contributors to seed yield per plot which could be taken in to consideration for future breeding program were the most important contributors to seed yield per plot which could be taken in consideration for future breeding program. Wide variability has been found among the genotypes for all the characters. The result of the study will provide the ability of breeders to develop desirable plant types having high seed yield, oil content and oil yield with early maturity. Analyzed value from genotypic coefficient of variation, heritability and genetic advance in percent of mean, correlation co-efficient and even path coefficient, oil yield, seed yield, oil content date $50 \%$ of flowering were the such traits which could be considered for future Linseed crop breeding program.

\section{REFERENCES}

[1] Abebe Delesa. 2006. Genetic Variability and Association Among Seed Yield and Yield Related Traits in Ethiopian mustard (Brassica carinata A. Braun) at Kulumsa, Arsi. An M.Sc. Thesis Presented to the School of Graduate Studies of Alemaya University. 75p.

[2] Adugna,W., and M.T. Labuschagne, 2002.Genotype-environment interactions and phenotypic stability analyses of linseed in Ethiopia. Plant Breeding 121 (1):66-71.

[3] Akbar M, Mahmood T, Anwar M, Ali M, Shafiq M, Salim J(2003). Linseed improvement through genetic variability, correlation and path coefficient analysis. International Journal of Agricultural Biology 5(3):303305.

[4] Ali, N., F. Javidfar, J.Y. Elmira and M.Y. Mirza. 2003. Relationship among yield components and selection criteria for yield improvement in winter rapeseed(Brassica napus L.).Pak. J. Bot. 35(2): 167-174

[5] Aytaç, Z. and G. Kınac. 2009. Genetic variability and association studies of some quantitative characters in 
winter rapeseed (Brassica napus L.). African Journal of Biotechnology, 8 (15): 3547-3554.

[6] CSA (CENTRAL STATISTICAL AUTHORITY), 2017/18.Time series data on area, production and yield of major crops, CSA, Addis Abeba, Ethiopia.

[7] Dewey, D.R. and K.H. Lu. 1959. A correlation and path coefficient analysis of

[8] components of crested wheat grass seed production. J. Agron. 51:515-518

[9] Jeromela, A.M., R. Marinkovic, A. Mijic, M. Jankulovska and Z. Zdunic. 2007. Interrelationship between oil Yield and Other Quantitative Traits in Rapeseed (Brassica napus L.). J. Central Eur. Agric. 8(2): 165-170

[10] Pali V, Mehta N.2013. Studies on genetic variability,correlation and path analysis for yield and its attributes in linseed (Linum usitatissimum L.). Plant Archives. 2013; 13(1):223-227.

[11] SAS Institute INC., 2002- 2008. SAS*STAT, users guide, version 9.2, Cary N.C., SAS INC

[12] Wakijira Adugna, 2011. Genetic variability among Linseed collections In.oil seeds Engine for economic Devt.Terefe G. A. wakijira and Derjie G.(Eds). Ethiopian Institute of Agricultural Research. Addis Ababa, Ethiopia, pp: 61-72.

[13] WWW:.premium crop.com Linseed A grower Guide).

[14] Yadav, Y. P. and S. Hari. 1996. Morpho-physiological determinants of yield under water stress condition in Indian mustard (Brassica juncea (L.) Czern and Coss.). Acta Horticulturea.

Citation: Fekadu Amsalu.," Genetic Variability, Correlation and Path Coefficient Analysis of Linseed (L/Numusitatissimum L) Genotypes” International Journal of Research Studies in Agricultural Sciences (IJRSAS), 2020; 6(12), pp. 12-20, 21-27 https://doi.org/10.20431/2454-6224.0612003

Copyright: (c) 2020 Authors. This is an open-access article distributed under the terms of the Creative Commons Attribution License, which permits unrestricted use, distribution, and reproduction in any medium, provided the original author and source are credited. 